\title{
Fabrication and Luminescence of Anodic Alumina with Incorporated Vanadyl Citrate Chelate Anions
}

\author{
Stępniowski $\mathrm{WJ}^{*}$, Norek $\mathrm{M}^{1}$, Michalska-Domańska $\mathrm{M}^{1}$, Nowak-Stępniowska $\mathrm{A}^{2}$, Kaliszewski $\mathrm{M}^{2}$, \\ Chilimoniuk $\mathrm{P}^{1}$, Bombalska $\mathrm{A}^{2}$ and Bojar $\mathrm{Z}^{1}$
}

${ }^{1}$ Department of advanced Materials and Technologies, Faculty of Advanced Technologies and Chemistry, Military University of Technology, Warszawa, Poland

${ }^{2}$ Institute of Optoelectronics, Military University of Technology, Warszawa, Poland

*Corresponding author: Stepniowski WJ, Department of Advanced Materials and Technologies, Faculty of Advanced Technologies and Chemistry, Military University of Technology, Str. Kaliskiego 2, 00-908 Warszawa, Poland, Fax: +48 2268394 45, Tel: +48 2268394 46, E-mail: wstepniowski@wat.edu.pl

Citation: Stępniowski WJ, Norek M, Michalska-Domańska M, Nowak-Stępniowska A, Kaliszewski M, et al. (2014) Fabrication and Luminescence of Anodic Alumina with Incorporated Vanadyl Citrate Chelate Anions. J Mater Sci Nanotechnol 1(1): S102. doi: 10.15744/2348-9812.1.S102

Received Date: April 10, 2014 Accepted Date: May 16, 2014 Published Date: May 19, 2014

\begin{abstract}
Anodic aluminum oxide doped with vanadyl citrate chelate complex anions was formed by a two-step self-organized anodization in 2 wt. \% sulfuric acid containing $0.04 \mathrm{M} \mathrm{V}_{2} \mathrm{O}_{5}$ and $0.08 \mathrm{M}$ citric acid at voltage range $13-23 \mathrm{~V}$, and at 0 and $15^{\circ} \mathrm{C}$. The combination of two temperatures and at least four voltages (depending on the applied temperature) was applied as the operating conditions of anodization. It was found that formed nanoporous alumina was doped with vanadium (up to 0.08 at. \%). The analysis of the photoluminescence of the grown oxide exhibits separate bands for the incorporated vanadyl citrate chelate anions (emission maxima at $\lambda=270 \mathrm{~nm}$ ) and $\mathrm{F}$ - centers (emission maxima at $\lambda=455 \mathrm{~nm}$ ). Moreover, due to the complex electronic structure of the incorporated anions, relatively long fluorescence decays were achieved (up to $44.6 \mathrm{~ns}$ ). Despite incorporation of relatively large anions, pore diameter and interpore distance were still linear functions of the voltage. Conducted research allowed to understand the fundamental aspects of the anions incorporation in the anodic alumina and allowed to form a new type of luminescent material.
\end{abstract}

Keywords: Oxides; Anodic aluminum oxide; Nanopores; Luminescence; Self-organization

\section{Introduction}

Anodization of aluminum allows to form self-organized, hexagonally-arranged, nanoporous anodic aluminum oxide (AAO). $\mathrm{AAO}$ attracts researchers attention due to the unlimited applications in numerous disciplines, including: nanofabrication [1-4], sensor assembly [1,5-6], high contact angle functional surface engineering [1,7-9], photonic crystals manufacturing [10-11], organic photovoltaics [12-13], and biomaterials fabrication [1,14-16].

Typically, highly-ordered AAO is fabricated in three major electrolytes: sulfuric [17-22], oxalic [17-18,23] and phosphoric acid $[8,17,18,24,25]$. So formed AAO is very often subjected to post processing to add some functional properties to the nanoporous oxide. Here one can distinguish ex-situ post-fabrication molecules loading into the AAO pores by simple impregnation [26], electrophoretical deposition of polymer nanoparticles [27], magnetic field assisted deposition of nanoparticles [28]. On the other hand, Thorat et al. reported various in-situ post-fabrication techniques of anodic alumina filling with silver nanoparticles [29]. All the mentioned above techniques are dedicated to already formed nanoporous alumina, and only the surface of inner pore walls can be functionalized. In the approach presented in the paper, the AAO is being functionalized during its growth - the in-situ real-time approach is presented and described. During anodic oxide growth, anions are being attracted by the anode, including the grown anodic oxide. Then, the attracted anions are being adsorbed on the anodic oxide surface and the gradually growing oxide is embedding them. As a result, electrolyte's anions are incorporated into the AAO, as demonstrated for instance by detailed study of Le Coz et al. reporting high resolution elemental mapping of AAO [24]. Moreover, a wide range of photoluminescence (PL) studies reveals that AAO has strong photoluminescence bands originating from incorporated electrolyte's anions and F-centers [3035]. Additionally, the fluorescence decay allows to distinguish bands originating from typical F-centers and those originating from the incorporated anions. For example, in studies reported by Li et al. [32] the F-centers fluorescence decay was shorter than 7 ns and the fluorescence decay originating from the anions was much longer, up to $46 \mathrm{~ns}$. Recently Shin et al. reported incorporation of $\mathrm{RuO}_{4}^{2-}$ anions into anodic titania during anodization, for catalytic purposes [36]. If the incorporation of typical anions occurs in anodic oxides, incorporation of more complex chemical individuals like chelate complexes should be also possible. 
In this paper incorporation of vanadyl citrate chelate complex into AAO is accomplished. The presence of vanadyl chelate complexes is confirmed by chemical composition analysis and photoluminescence studies.

\section{Materials and Methods}

At first, series of $\mathrm{V}_{2} \mathrm{O}_{5}$ solutions were prepared in $2 \mathrm{wt}$. $\% \mathrm{H}_{2} \mathrm{SO}_{4}$ with and without addition of citric acid. Spectra of $\mathrm{V}_{2} \mathrm{O}_{5}$ in $\mathrm{H}_{2} \mathrm{SO}_{4}$ and $\mathrm{V}_{2} \mathrm{O}_{5}$ in $\mathrm{H}_{2} \mathrm{SO}_{4}$ with citric acid were taken with UV-Vis Cary spectrophotometer (Varian Company) at wavelength range from 250 to $1000 \mathrm{~nm}$. Solution with citric acid left overnight turned blue what confirmed appearance of $\mathrm{VO}^{2+}$ cations chelated by citrate anions (electronic transition between orbitals in accordance to the ligand field theory).

A high purity Al foil purchased from Alfa Aesar (99.9995\% Puratronic) was cut into coupons $(1 \mathrm{~cm}$ per $2.5 \mathrm{~cm}$ ), degreased in acetone and ethanol and electropolished (Pt grid as a cathode, mixture of 4:1 ethanol: $60 \% \mathrm{HClO}_{4}$ by volume, $10{ }^{\circ} \mathrm{C}, 0.5 \mathrm{~A} / \mathrm{cm}^{2}, 60$ s). Anodizations were carried out in $0.04 \mathrm{M} \mathrm{V}_{2} \mathrm{O}_{5}$ with 0.08 citric acid in $2 \mathrm{wt} . \% \mathrm{H}_{2} \mathrm{SO}_{4}$ in the voltage range from 13 to $23 \mathrm{~V}$ with step of $2 \mathrm{~V}$ at 0 and $15^{\circ} \mathrm{C}$. After the first, $20 \mathrm{~h}$ long anodization, the poorly arranged oxide was removed by chemical etching in a mixture of stirred $6 \mathrm{wt} . \% \mathrm{H}_{3} \mathrm{PO}_{4}$ and $1.8 \mathrm{wt} . \mathrm{H}_{2} \mathrm{CrO}_{4}$ at $60^{\circ} \mathrm{C}$ for $90 \mathrm{~min}$. After oxide removal, the re-anodization was conducted at the same set of experimental conditions like the first step.

Characterization of the anodic oxide was done with a high-resolution field emission scanning electron microscope (FE-SEM) Quanta 3D FEG (FEI, USA). Geometrical features like pore diameter and interpore distance were evaluated from three independent FE-SEM micrographs and the image analysis were performed with NIS-Elements and WSxM software $[37,38]$. The thickness of AAO were evaluated from cross sections.

Chemical composition of the anodic aluminum oxide was measured by use of the FE-SEM equipped with X-ray energy dispersive spectroscope (EDS) at voltage of $20 \mathrm{kV}$. The EDS analyses were performed for cross sections of AAO, to avoid any systematic errors from unoxidized aluminum beneath the porous oxide layer.

The PL spectra were taken with FL 900 spectrofluorimeter (Edinburgh Instruments) with Xe lamp, using front-surface measurement mode. The excitation spectra were taken from 245 to $400 \mathrm{~nm}$ and emission spectra from 260 to $550 \mathrm{~nm}$ what allowed to evaluate photoluminescence excitation-emission maps.

Fluorescence decays (FD) of the samples were measured with stroboscopic technique with the use of EasyLife LS system PTI. Two impulse diode modules generating 280 and $340 \mathrm{~nm}$ were employed for sample excitation. Wide characteristics of the diodes were corrected with filters (Semrock) FF-280/20 and FF-340/26, respectively. Long-pass filters, cutting-off excitation band, on emission path were used: FF-300LP and LP-355 for 280 and $340 \mathrm{~nm}$ excitation, respectively. FD characteristics were collected at room temperature using 10 averages. The pieces of the solid samples were fixed with holder with the use of quartz Suprasil ${ }^{\mathrm{TM}}$ window. The holder allowed fluorescence signal collection from the surface. Instrument Response Function (IRF) was recorded using blank aluminum sample. The procedure was conducted separately for 280 and $340 \mathrm{~nm}$ excitation sources. In both cases corresponding excitation filters were placed in optical paths. Deconvolution of IRF and sample signals was performed with the use of FELIX32 program. Two or three lifetime component model was chosen depending on the best fitting regarding $\chi^{2}$ parameter.

\section{Results and discussion}

Figure la shows absorption spectra of $0.04 \mathrm{M} \mathrm{V}_{2} \mathrm{O}_{5}$ dissolved in $2 \mathrm{wt}$. $\% \mathrm{H}_{2} \mathrm{SO}_{4}$ with and without addition of $0.08 \mathrm{M}$ citric acid. For solution with citric acid a distinct maximum is seen, which, according to Gryboś et al. [39] should be attributed to the electronic transitions between d-orbitals of $\mathrm{VO}^{2+}$ chelated ions (from 713 to $833 \mathrm{~nm}$ there are bands attributed to the $\mathrm{d}_{\mathrm{xy}} \rightarrow \mathrm{d}_{\mathrm{yz}}, \mathrm{d}_{\mathrm{xz}}$ transitions). Additionally, according to the paper of Niklova and Niklov [40], at low pH, depending on the ligand to central cation ratio, citrate vanadyl complexes have absorption maxima at the wavelength range from 550 to $830 \mathrm{~nm}$. In this work, the absorption maximum of the vanadyl citrate chelate complex is at $\lambda=770 \mathrm{~nm}$, which is in line with the results cited above. At low wavelength region, there was extremely intensive absorption maximum at the $200 \mathrm{~nm}$, attributed to the electronic transitions between the bonding and anti-bonding $\pi$ orbitals (Figure $1 \mathrm{~b}$; recorded for diluted solution). It confirms that $\left[\mathrm{VO}\left(\mathrm{H}_{2} \mathrm{O}\right)_{2}(\mathrm{cit})\right]^{-}$chelate complex was formed. To incorporate desired elements into anodic aluminum oxide, they have to be in a form of anion, to be attracted by the anode. Therefore, stable chelate complex enables anodic alumina doping with $\mathrm{VO}^{2+}$ cations chelated by citrates. Nevertheless, one has to be aware that in sulfuric acid solution the citrates may protonate and various interconversions may be also take place [41]. Moreover, citrates have also one major advantage as an electrolyte modifier applied in anodization - they prevent anode from current-assisted dissolution for anodizing at low voltages [42]. Therefore, anodization at $13 \mathrm{~V}$ was enabled.

After two-step, self-organized anodization performed in $2 \mathrm{wt}$. $\% \mathrm{H}_{2} \mathrm{SO}_{4}$ containing $0.04 \mathrm{M} \mathrm{V}_{2} \mathrm{O}_{5}$ and $0.08 \mathrm{M}$ citric acid, nanoporous oxide was formed, with quite uniform pores and satisfying arrangement at all different anodization voltages considered (13, 15 and $17 \mathrm{~V}$ for Figure $2 \mathrm{a}, \mathrm{b}$ and c, respectively). The oxide contained vanadium, up to 0.08 at. \% (Table 1 ). The presence of vanadium in the form of chelate complex was aconfirmed by the recorded photoluminescence maps (Figure $2 \mathrm{~d}$-f). The relevant quantitative information concerning AAO geometry and amount of incorporated vanadyl has been summarized in Tables 1 and 3 , respectively. 

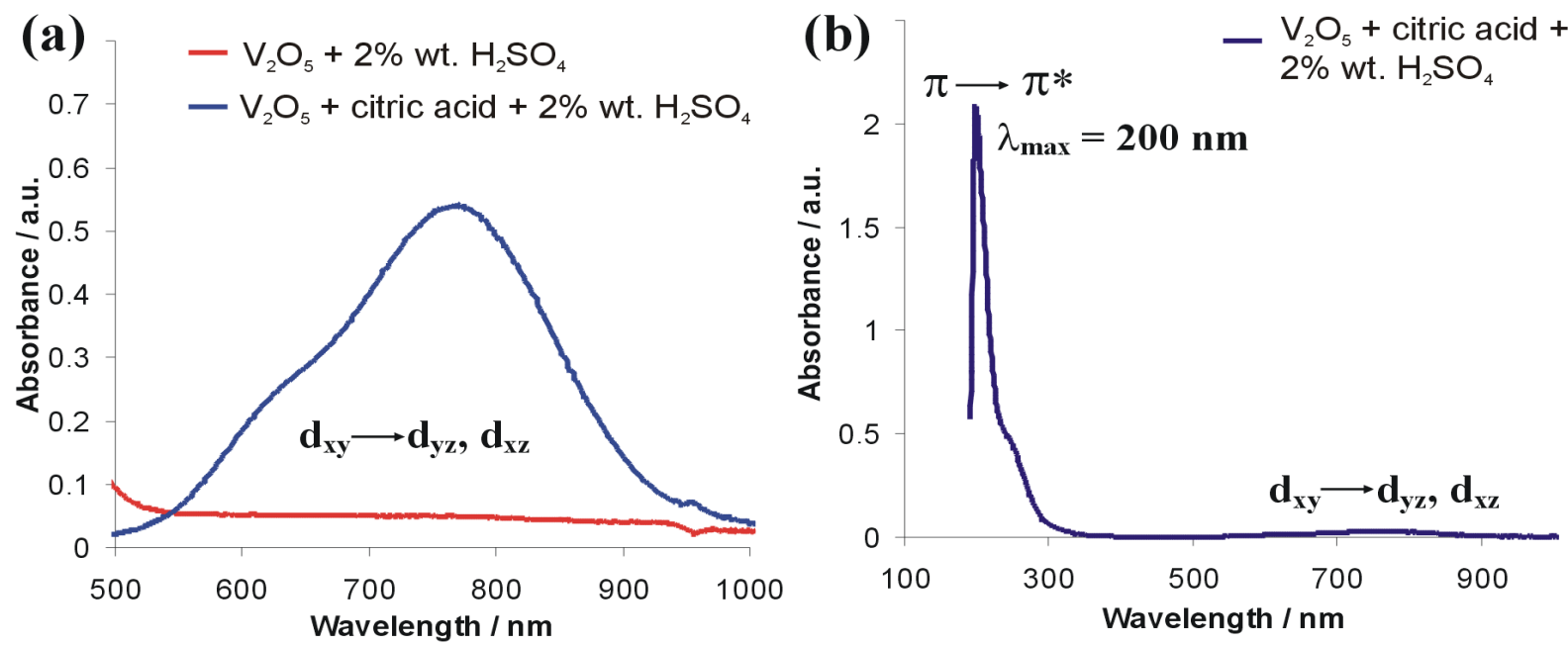

Figure 1: Absorption spectra of $0.04 \mathrm{M} \mathrm{V}_{2} \mathrm{O}_{5}$ in 2 wt. $\% \mathrm{H}_{2} \mathrm{SO}_{4}$ and $0.04 \mathrm{M} \mathrm{V}_{2} \mathrm{O}_{5}$ with 0.08 citric acid in 2 wt. $\% \mathrm{H}_{2} \mathrm{SO}_{4}$ (a) and for $2.10^{-4} \mathrm{M}$ $\mathrm{V}_{2} \mathrm{O}_{5}$ with $4.10^{-4}$ citric acid in 2 wt. $\% \mathrm{H}_{2} \mathrm{SO}_{4}$

For the lowest excitation wavelengths, starting from $245 \mathrm{~nm}$, emission band with low intensity are seen on the maps, especially for AAO formed at $17 \mathrm{~V}$ (Figure $2 \mathrm{f}$ ). These can be attributed to the incorporated vanadyl citrate chelate complexes, namely to the excitation of electrons from bonding to anti-bonding $\pi$ orbitals (compare to Figure $1 \mathrm{~b}$ ). It is clearly seen in the maps that in the excitation wavelengths $325-400 \mathrm{~nm}$ range strong emission occurs in the $380-520 \mathrm{~nm}$ range what can be attributed to the $\mathrm{F}$ centers of the anodic aluminum oxide.
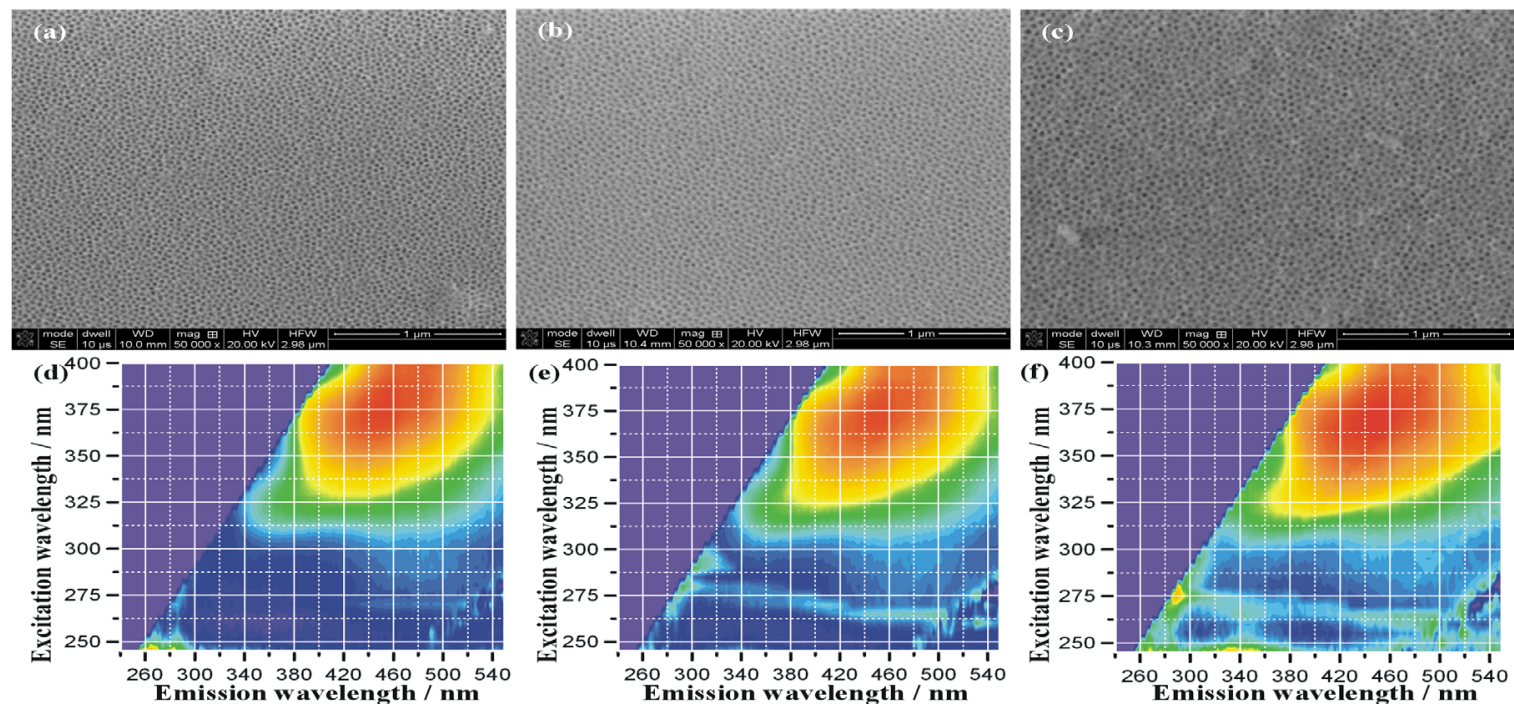

Figure 2: FE-SEM micrographs (a-c) and PL excitation-emission maps (d-f) of AAO formed in 2 wt. \% $\mathrm{H}_{2} \mathrm{SO}_{4}$ with addition of $0.04 \mathrm{M}$ $\mathrm{V}_{2} \mathrm{O}_{5}$ and 0.08 citric acid at $15^{\circ} \mathrm{C}$ at $13(\mathrm{a}, \mathrm{d}), 15(\mathrm{~b}, \mathrm{e})$ and $17 \mathrm{~V}(\mathrm{c}, \mathrm{f})$. The hotter color the greater PL intensity (d-f).

Detailed PL analysis, performed for excitation wavelength of 220, 280, 340 and $380 \mathrm{~nm}$, shows emission intensity maxima for most of the samples at about $455 \mathrm{~nm}$ (Figure 3). However, for the lowest excitation wavelength there are intensive bands with maxima at about $270 \mathrm{~nm}$ (Figure 3a), which have not been reported for AAO in the literature yet. Hence, these can be attributed to the incorporated vanadyl citrate chelate anions. Typical F-centers PL emission wavelengths are in the range of 440 - 500 nm [30-35], as well as the emission wavelengths of incorporated sulfate anions [32]. In general, at each anodization voltage, the greatest emission intensities were recorded for AAO formed at $15{ }^{\circ} \mathrm{C}$ (Figure 3). However obtained chemical composition analysis of the formed oxide, due to the detection threshold and small amount of incorporated chelate complex anions, does not give clear foundations for any statement about correlation between the photoluminescence and the operating conditions of the anodization process. One can also notice that for AAO formed at $15^{\circ} \mathrm{C}$ at $19 \mathrm{~V}$ the PL intensity is the lowest one. However, for this operating conditions, anodic dissolution was dominating in several zones and the AAO was dissolved there, what affected the PL intensity. 


\begin{tabular}{|c|c|c|c|c|}
\hline Temperature $\left[{ }^{\circ} \mathbf{C}\right]$ & Voltage $[\mathbf{V}]$ & Vanadium content [at. \%] & Oxide layer thickness $[\boldsymbol{\mu m}]$ & Average Current Density $\left[\mathbf{m A} / \mathbf{c m}^{2}\right]$ \\
\hline \multirow{5}{*}{0} & 13 & $0.04 \pm 0.02$ & $6.1 \pm 0.1$ & $0.1 \pm 0.1$ \\
\cline { 2 - 5 } & 15 & $0.05 \pm 0.01$ & $7.5 \pm 0.2$ & $0.5 \pm 0.4$ \\
\cline { 2 - 5 } & 17 & $0.04 \pm 0.01$ & $9.9 \pm 0.2$ & $0.7 \pm 0.1$ \\
\cline { 2 - 5 } & 19 & $0.04 \pm 0.01$ & $13.2 \pm 0.1$ & $1.8 \pm 0.7$ \\
\cline { 2 - 5 } & 21 & $0.06 \pm 0.01$ & $13.0 \pm 0.3$ & $1.8 \pm 0.5$ \\
\hline \multirow{3}{*}{15} & 13 & $0.08 \pm 0.02$ & $17.0 \pm 0.3$ & $0.8 \pm 0.4$ \\
\cline { 2 - 5 } & 15 & $0.05 \pm 0.02$ & $15.6 \pm 1.2$ & $0.7 \pm 0.1$ \\
\cline { 2 - 5 } & 17 & $0.05 \pm 0.01$ & $18.0 \pm 0.5$ & $1.0 \pm 0.1$ \\
\cline { 2 - 5 } & 19 & $0.05 \pm 0.02$ & $23.5 \pm 0.7$ & $1.6 \pm 0.3$ \\
\hline
\end{tabular}

Table 1: Percentage content of vanadium in $\mathrm{AAO}$ formed in $2 \mathrm{wt} . \% \mathrm{H}_{2} \mathrm{SO}_{4}$ with chelate vanadyl complex additives with fabrication conditions and oxide thickness.

\begin{tabular}{|c|c|c|c|c|c|c|c|c|}
\hline \multirow{2}{*}{ Temperature $\left[{ }^{\circ} \mathrm{C}\right]$} & \multirow{2}{*}{ Voltage [V] } & \multicolumn{4}{|c|}{ Excitation wavelength $\lambda_{\text {exc }}=280 \mathrm{~nm}$} & \multicolumn{3}{|c|}{ Excitation wavelength $\lambda_{\text {exc }}=340 \mathrm{~nm}$} \\
\hline & & Lifetime [n & Percen & $\begin{array}{l}\text { gee share } \\
\text { \%] }\end{array}$ & Attribution & $\begin{array}{c}\text { Lifetime } \\
{[\text { [ns] }}\end{array}$ & $\begin{array}{c}\text { Percentage } \\
\text { share [\%] }\end{array}$ & Attribution \\
\hline \multirow{6}{*}{0} & 13 & $\begin{array}{l}\text { No fluoresc } \\
\text { AAO fc }\end{array}$ & $\begin{array}{l}\text { nce decay an } \\
\text { med at this se }\end{array}$ & $\begin{array}{l}\text { ysis could } \\
\text { of operat }\end{array}$ & $\begin{array}{l}\text { be performed for } \\
\text { ng conditions }\end{array}$ & $\begin{array}{l}0.8 \pm 0.1 \\
2.6 \pm 0.7 \\
5.6 \pm 0.6\end{array}$ & $\begin{array}{c}82.9 \pm 5.1 \\
11.0 \pm 3.4 \\
6.2 \pm 2.3\end{array}$ & \multirow{9}{*}{ 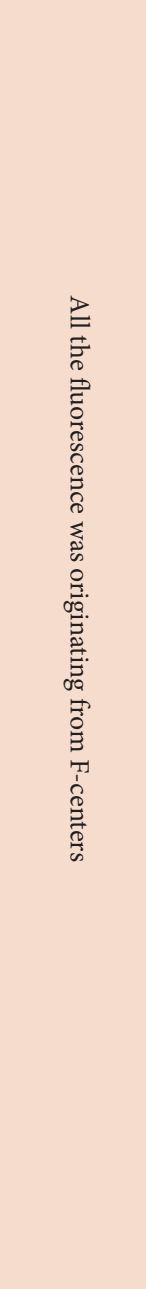 } \\
\hline & 15 & $\begin{array}{c}0.7 \pm 0.1 \\
3.2 \pm 0.1 \\
38.9 \pm 3.8\end{array}$ & $\begin{array}{c}73.2 \pm 4.2 \\
26.1 \pm 1.0 \\
0.8 \pm 0.0\end{array}$ & Incorpo & $\begin{array}{l}\text { F-centers } \\
\text { F-centers } \\
\text { rated chelate anions }\end{array}$ & $\begin{array}{l}1.0 \pm 0.0 \\
4.6 \pm 0.1\end{array}$ & $\begin{array}{l}88.1 \pm 5.5 \\
11.9 \pm 0.4\end{array}$ & \\
\hline & 17 & $\begin{array}{c}0.7 \pm 0.1 \\
2.7 \pm 0.0 \\
44.6 \pm 1.0\end{array}$ & $\begin{array}{c}43.6 \pm 4.6 \\
55.1 \pm 1.5 \\
1.2 \pm 0.0\end{array}$ & Incorpo & $\begin{array}{l}\text { F-centers } \\
\text { F-centers } \\
\text { rated chelate anions }\end{array}$ & $\begin{array}{l}0.9 \pm 0.0 \\
4.6 \pm 0.1\end{array}$ & $\begin{array}{c}90.8 \pm 5.7 \\
9.2 \pm 0.3\end{array}$ & \\
\hline & 19 & $\begin{array}{c}0.9 \pm 0.0 \\
3.3 \pm 0.1 \\
35.2 \pm 5.2\end{array}$ & $\begin{array}{c}75.83 \pm 3.5 \\
23.42 \pm 1.6 \\
0.75 \pm 0.0\end{array}$ & Incorpo & $\begin{array}{l}\text { F-centers } \\
\text { F-centers } \\
\text { rated chelate anions }\end{array}$ & $\begin{array}{l}1.1 \pm 0.0 \\
4.7 \pm 0.1\end{array}$ & $\begin{array}{l}85.9 \pm 4.2 \\
14.1 \pm 0.5\end{array}$ & \\
\hline & 21 & $\begin{array}{c}0.5 \pm 0.0 \\
3.4 \pm 0.1 \\
33.5 \pm 1.0\end{array}$ & $\begin{array}{c}84.3 \pm 5.7 \\
14.9 \pm 0.4 \\
0.9 \pm 0.0\end{array}$ & Incorpo & $\begin{array}{l}\text { F-centers } \\
\text { F-centers } \\
\text { rated chelate anions }\end{array}$ & $\begin{array}{l}1.1 \pm 0.0 \\
4.7 \pm 0.1\end{array}$ & $\begin{array}{l}86.0 \pm 5.2 \\
14.0 \pm 0.5\end{array}$ & \\
\hline & 23 & $\begin{array}{c}0.5 \pm 0.1 \\
3.1 \pm 0.1 \\
41.7 \pm 3.8\end{array}$ & $\begin{array}{c}81.3 \pm 6.4 \\
18.0 \pm 0.8 \\
0.7 \pm 0.0\end{array}$ & Incorpo & $\begin{array}{l}\text { F-centers } \\
\text { F-centers } \\
\text { rated chelate anions }\end{array}$ & $\begin{array}{l}1.0 \pm 0.0 \\
5.2 \pm 0.1\end{array}$ & $\begin{array}{c}91.0 \pm 6.0 \\
9.0 \pm 0.3\end{array}$ & \\
\hline \multirow{4}{*}{15} & 13 & $\begin{array}{c}0.6 \pm 0.1 \\
2.7 \pm 0.0 \\
43.8 \pm 0.5\end{array}$ & $\begin{array}{c}40.4 \pm 6.0 \\
58.2 \pm 1.2 \\
1.4 \pm 0.0\end{array}$ & Incorpo & $\begin{array}{l}\text { F-centers } \\
\text { F-centers } \\
\text { rated chelate anions }\end{array}$ & $\begin{array}{l}1.2 \pm 0.0 \\
5.0 \pm 0.1\end{array}$ & $\begin{array}{l}83.8 \pm 4.3 \\
16.2 \pm 0.4\end{array}$ & \\
\hline & 15 & $\begin{array}{c}0.7 \pm 0.0 \\
3.3 \pm 0.1 \\
25.2 \pm 1.9\end{array}$ & $\begin{array}{c}80.6 \pm 4.6 \\
19.0 \pm 0.1 \\
0.4 \pm 0.0\end{array}$ & Incorpo & $\begin{array}{l}\text { F-centers } \\
\text { F-centers } \\
\text { rated chelate anions }\end{array}$ & $\begin{array}{l}1.1 \pm 0.1 \\
4.6 \pm 0.1\end{array}$ & $\begin{array}{l}86.4 \pm 5.2 \\
13.6 \pm 0.6\end{array}$ & \\
\hline & 17 & $\begin{array}{c}0.7 \pm 0.0 \\
3.4 \pm 0.1 \\
16.3 \pm 0.8\end{array}$ & $\begin{array}{c}77.5 \pm 4.1 \\
21.2 \pm 0.1 \\
1.3 \pm 0.1\end{array}$ & Incorpo & $\begin{array}{l}\text { F-centers } \\
\text { F-centers } \\
\text { rated chelate anions }\end{array}$ & $\begin{array}{l}1.1 \pm 0.1 \\
4.6 \pm 0.1\end{array}$ & $\begin{array}{l}83.5 \pm 5.4 \\
16.5 \pm 0.6\end{array}$ & \\
\hline & 19 & \multicolumn{7}{|c|}{ No fluorescence decay analysis could be performed for AAO formed at this set of operating conditions } \\
\hline
\end{tabular}

Table 2: Fluorescence decay after deconvolution into three peaks of $\mathrm{AAO}$ formed in $2 \mathrm{wt} . \mathrm{H}_{2} \mathrm{SO}_{4}$ with chelate vanadyl complex additives with fabrication conditions. The samples were excited with radiation wavelength of $\lambda=280 \mathrm{~nm}$ and $340 \mathrm{~nm}$. 
To confirm the origin of PL bands, a fluorescence decay of AAO was investigated in details. Typically, the F-centers fluorescence decay is shorter than $7 \mathrm{~ns}$ and for other individuals, like incorporated anions, the decay time is longer, due to the complexity of phenomena of energy transfers between the bands of more sophisticated structures [32]. In all the cases, while the samples were excited with $\lambda_{\text {exc }}=280 \mathrm{~nm}$, the fluorescence decay was described by three main components: two shorter than $7 \mathrm{~ns}$ and one much longer than $7 \mathrm{~ns}$, reaching even up to approximately $45 \mathrm{~ns}$ (Table 2).

Therefore, the longest fluorescence decays can be surely attributed to the incorporated vanadyl chelate complex anions and the two shorter ones - to the F-centers. However, the share of the relatively long fluorescence decays was just about $1 \%$ what is caused by low content of vanadyl citrate chelate complexes (Table 1 ) and excitation wavelength (compare Figure 2a to Figure $2 \mathrm{~b}$ ). Nevertheless, fluorescence decays, longer than $7 \mathrm{~ns}$ were recorder for all the samples, what confirms the presence of relatively complex structures present in the AAO, excited with $\lambda_{\text {exc }}=280 \mathrm{~nm}$. Analysis of fluorescence decays for AAO excited with $\lambda_{\text {exc }}=360 \mathrm{~nm}$ shows any fluorescence decays longer than $7 \mathrm{~ns}$ (Table 2). Therefore, all the emission bands in the range of $380-520 \mathrm{~nm}$ can be attributed to the F - centers.

Incorporation of relatively large chelate anions has not affected strongly the AAO itself. One can see quite regular pores (Figure 2) which geometrical features like pore diameter and interpore distance are still controlled by the voltage (Table 3). Pore diameter increase with the temperature is noticed (Table 3). Thus, a geometry-controllable AAO template with luminescent properties owed to the incorporated anions was formed. A phenomenological explanation of the observed effects can be given, based on a recent theoretical formulation of the AAO growth mechanism [43]. Despite local $\mathrm{pH}$ and viscosity fluctuations [43], the anode attracts various anions like $\mathrm{O}^{2-}$ and $\mathrm{OH}^{-}$, as well as the electrolyte's anions: $\mathrm{SO}_{4}^{2-}$ (Figure 4).

\begin{tabular}{|c|c|c|c|c|c|}
\hline Temperature $\left[{ }^{\circ} \mathrm{C}\right]$ & Voltage [V] & Pore diameter [nm] & $\begin{array}{c}\text { Interpore distance } \\
{[\mathrm{nm}]}\end{array}$ & Porosity [\%] & $\begin{array}{c}\text { Pores density } \\
{\left[\mu \mathrm{m}^{-}\right]}\end{array}$ \\
\hline \multirow{6}{*}{0} & 13 & $21 \pm 5$ & $41 \pm 1$ & $24 \pm 11$ & $406 \pm 32$ \\
\hline & 15 & $22 \pm 3$ & $43 \pm 1$ & $24 \pm 7$ & $413 \pm 54$ \\
\hline & 17 & $23 \pm 3$ & $47 \pm 1$ & $22 \pm 7$ & $394 \pm 6$ \\
\hline & 19 & $25 \pm 5$ & $53 \pm 1$ & $20 \pm 9$ & $307 \pm 8$ \\
\hline & 21 & $27 \pm 7$ & $58 \pm 5$ & $20 \pm 13$ & $277 \pm 10$ \\
\hline & 23 & $28 \pm 6$ & $62 \pm 3$ & $18 \pm 9$ & $259 \pm 13$ \\
\hline \multirow{4}{*}{15} & 13 & $26 \pm 4$ & $39 \pm 0$ & $40 \pm 11$ & $476 \pm 69$ \\
\hline & 15 & $26 \pm 3$ & $44 \pm 0$ & $32 \pm 8$ & $437 \pm 8$ \\
\hline & 17 & $30 \pm 4$ & $50 \pm 1$ & $32 \pm 9$ & $294 \pm 19$ \\
\hline & 19 & $31 \pm 7$ & $52 \pm 1$ & $31 \pm 15$ & $299 \pm 19$ \\
\hline \multicolumn{6}{|c|}{ Equations of the fitting curves } \\
\hline & \multicolumn{2}{|c|}{ Temperature $0^{\circ} \mathrm{C}$} & \multicolumn{3}{|c|}{ Temperature $15^{\circ} \mathrm{C}$} \\
\hline Pore diameter & \multicolumn{2}{|c|}{$\mathrm{Dp}=0.71 \mathrm{U}+11.67$} & \multicolumn{3}{|c|}{$\mathrm{Dp}=0.89 \mathrm{U}+13.79$} \\
\hline Intepore distance & \multicolumn{2}{|c|}{$\mathrm{Dc}=2.21 \mathrm{U}+10.83$} & \multicolumn{3}{|c|}{$\mathrm{Dc}=2.25 \mathrm{U}+10.29$} \\
\hline
\end{tabular}

Table 3: Geometrical features of formed AAO with operating conditions.
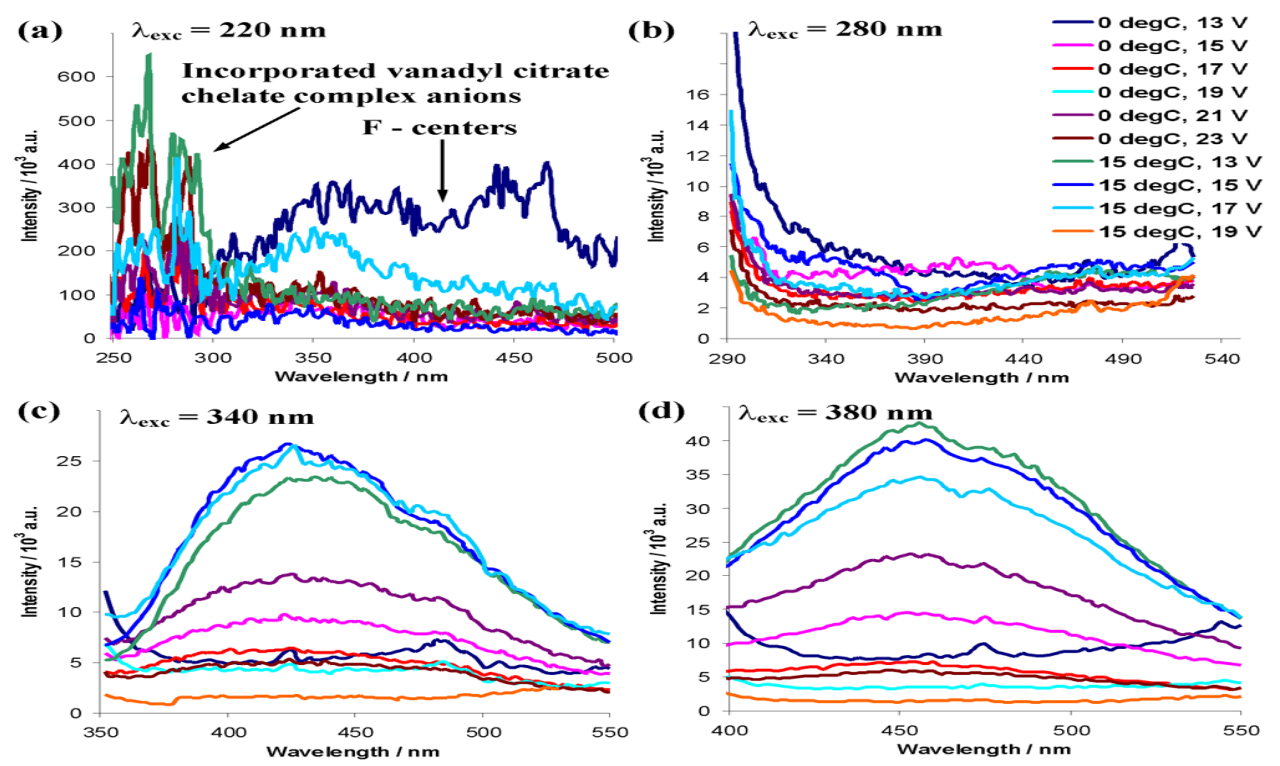

Figure 3: PL spectra of AAO formed in 2 wt. $\% \mathrm{H}_{2} \mathrm{SO}_{4}$ with addition of $0.04 \mathrm{M} \mathrm{V}_{2} \mathrm{O}_{5}$ and 0.08 citric acid. AAO was excited with various radiation wavelengths: 220 (a), 280 (b), 340 (c) and 380 (d). 


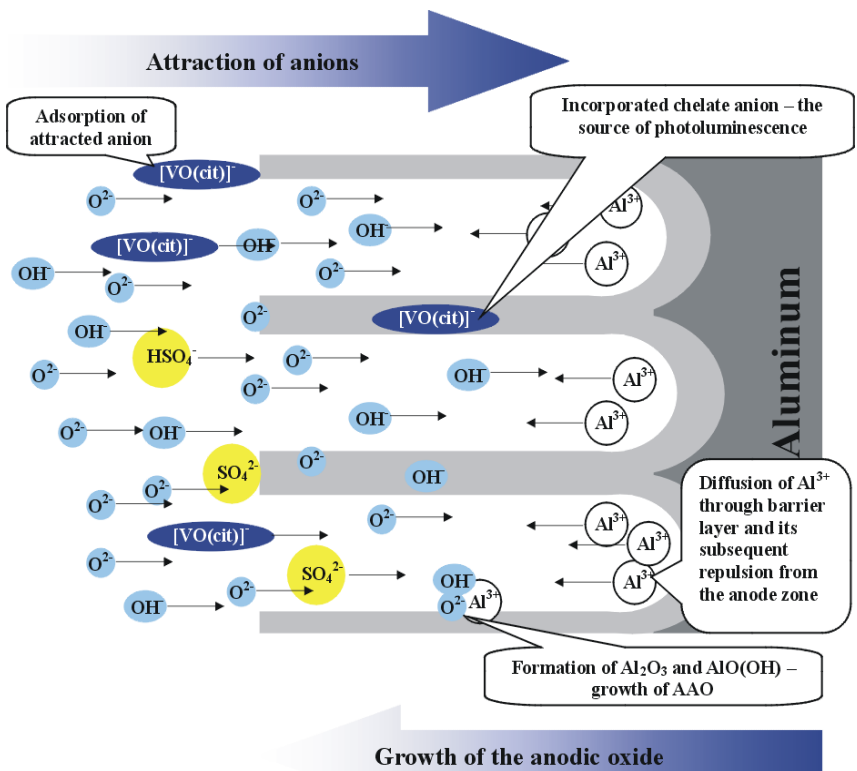

Figure 4: Schematic presentation of the phenomena occurring during anodic oxide growth, leading to the incorporation of [VO(cit)]:

The chelate complex anions, present in the solution, are also attracted by the anode. Simultaneously, $\mathrm{Al}^{3+}$ are being repulsed from the anode and form alumina and aluminum oxide-hydroxide in contact with $\mathrm{O}^{2-}$ and $\mathrm{O}^{2-}$ with $\mathrm{OH}^{-}$respectively. On the same time, sulfate and vanadyl citrate anions are attracted and adsorbed on the oxide surface. Gradual growth of the AAO makes the adsorbed anions surrounded by the grown anodic oxide, which translates into incorporation of anionic species into the AAO (Figure 4). Therefore, both geometry control and transition metal doping of AAO can be done by operating conditions control and the formed template may have desired pore diameter, interpore distance and luminescent properties owed to the incorporated anions.

\section{Conclusions}

Anodic aluminum oxide with incorporated vanadyl citrate chelate complex anions has been formed. Incorporated anionic species influence the luminescent properties of the grown oxide. The main conclusions can be summarized in few points:

- Introduction of stabile, complex anions into electrolyte allows to form anodic alumina doped with these anions.

- The photoluminescence of vanadyl chelate anions has excitation and emission wavelengths much shorter than $\mathrm{F}-$ centers, what makes them distinguishable. Moreover, fluorescence decays of the incorporated anions are relatively long and in particular cases exceeds even 40 ns.

- Anodic alumina geometry control by operating conditions was conserved, despite the incorporation of relatively large anions.

\section{References}

1. Jani AMM, Losic D, Voelcker NH (2013) Nanoporous anodic aluminium oxide: Advances in surface engineering and emerging applications. Prog Mater Sci 58: 636-704.

2. Jagminas A, Mažeika K, Reklaitis J, Pakštas V, Baltrūnas D (2009) Annealing effects on the transformations of Fe nanowires encapsulated in the alumina template pores. Mat Chem Phys 115: 217-22.

3. Zhao GY, Li HL (2008) Preparation of polyaniline nanowire arrayed electrodes for electrochemical supercapacitors. Micropor Mesopor Mater 110: 590-94.

4. Yu Y, Kant K, Shapter JG, Addai-Mensah J, Losic D (2012) Gold nanotube membranes have catalytic properties. Micropor Mesopor Mater 153: 131-36.

5. Claussen JC, Wickner MW, Fisher TS, Porterfield TM (2011) Transforming the fabrication and biofunctionalization of gold nanoelectrode arrays into versatile electrochemical glucose biosensors. ACS Appl Mater Interfaces 3: 1765-70.

6. Santos A, Macías G, Ferré-Borrull J, Pallarès J, Marsal LF (2012) Photoluminescent enzymatic sensor based on nanoporous anodic alumina. ACS Appl Mater Interfaces 4: 3584-8.

7. Romero V, Vega V, García J, Zierold R, Nielsch K, et al. (2013) Changes in morphology and ionic transport induced by $\mathrm{ALD} \mathrm{SiO}_{2}$ coating of nanoporous alumina membranes. ACS Appl Mater Interfaces 5: 3556-64.

8. Buijnsters JG, Zhong R, Tsyntsaru N, Celis JP (2013) Surface wettability of macroporous anodized aluminum oxide. ACS Appl Mater Interfaces 5: 3224-33.

9. Velleman L, Triani G, Evans PJ, Shapter JG, Losic D (2009) Structural and chemical modification of porous alumina membranes. Micropor Mesopor Mater 126: 87-94.

10. Choi J, Luo Y, Wehrspohn RB, Hillebrand R, Schilling J, et al. (2003) Perfect two-dimensional porous alumina photonic crystals with duplex oxide layers. J Appl Phys 94: 4757-62.

11. Masuda H, Ohya M, Nishio K, Asoh H, Nakao M, et al. (2000) Photonic band gap in anodic porous alumina with extremely high aspect ratio formed in phosphoric acid solution. Jpn J Appl Phys 39: L1039-41.

12. Wiedemann W, Sims L, Abdellah A, Exner A, Meier R, et al. (2010) Nanostructured interfaces in polymer solar cells. Appl Phys Lett 96: 263109.

13. Kim JS, Park Y, Lee DY, Lee JH, Park JH, et al. (2010) Poly(3-hexylthiophene) nanorods with aligned chain orientation for organic photovoltaics. Adv Funct Mater 20: 540-5.

14. Karlsson M, Palsgard E, Wilshaw PR, Di Silvio L (2003) Initial in vitro interaction of osteoblasts with nano-porous alumina. Biomater 24: $3039-46$. 
15. Lee JH, Kim DN, Park S, Lee Y, Koh WG (2011) Micropatterning of a nanoporous alumina membrane with poly(ethylene glycol) hydrogel to create cellular micropatterns on nanotopographic substrates. Acta Biomater 7: 1281-9.

16. Salerno M, Caneva-Soumetz F, Pastorino L, Patra N, Diaspro A, et al. (2013) Adhesion and proliferation of osteoblast-like cells on anodic porous alumina substrates with different morphology. IEEE Trans Nanobiosci 12: 106-11.

17. Ono S, Masuko N (2003) Evaluation of pore diameter of anodic porous films formed on aluminum. Surf Coat Technol 169-170: 139-42.

18. Nielsch K, Choi J, Schwirn K, Wehrspohn RB, Gösele U (2002) Self-ordering regimes of porous alumina: the 10\% porosity rule. Nano Lett 2: 677-80.

19. Beck G, Bretzler R (2011) Regularity of nanopores in anodic alumina formed on orientated aluminium single-crystals. Mat Chem Phys 128: 383-7.

20. Beck G (2012) Alternating nanopore diameters in anodic alumina grown within aluminium tubes. Mat Chem Phys 137: 5-11.

21. Tang S, Zhou H, Liu S, Fu C, Huang Z, et al. (2013) Effects of a pre-existed anodic alumina on successive anodization behavior of aluminum and structure of its oxide film. Mat Chem Phys 139: 339-44.

22. Manzano CV, Martín J, Martín-González MS (2013) Ultra-narrow 12 nm pore diameter self-ordered anodic alumina templates. Micropor Mesopor Mater 184: 177-83.

23. Noormohammadi M, Moradi M (2012) Structural engineering of nanoporous alumina by direct cooling the barrier layer during the aluminum hard anodization. Mat Chem Phys 135: 1089-95.

24. Le Coz F, Arurault L, Datas L (2010) Chemical analysis of a single basic cell of porous anodic aluminium oxide templates. Mater Character 61: 283-8.

25. Martín J, Manzano CV, Martín-González MS (2012) In-depth study of self-ordered porous alumina in the 140-400 nm pore diameter range. Micropor Mesopor Mater 151: 311-6.

26. Moahden A, Elhouichet H, Nosova L, Oueslati M (2007) Rhodamine B absorbed by anodic porous alumina: Stokes and anti-Stokes luminescence study. J Luminescence 126: 789-94.

27. Gultepe E, Nagesha D, Menon L, Busnaina A, Sridhar S (2007) High-throughput assembly of nanoelements in nanoporous alumina templates. Appl Phys Lett 90: 163119.

28. Seo I, Kwon CW, Lee HH, Kim YS, Kim KB, et al. (2009) Completely filling anodic aluminum oxide with maghemite nanoparticles by dip coating and their magnetic properties. Electrochem Solid-State Lett 12: K59-62.

29. Thorat S, Diaspro A, Scarpellini A, Povia M, Salerno M (2013) Comparative study of loading of anodic porous alumina with silver nanoparticles using different methods. Materials 6: 206-16.

30. Rauf A, Mehmood M, Ahmed M, ul Hasan M, Aslam M (2010) Effects of ordering quality of the pores on the photoluminescence of porous anodic alumina prepared in oxalic acid. J Luminescence 130: 792-800.

31. Li Z, Huang K (2007) Optical properties of alumina membranes prepared by anodic oxidation process. J Luminescence 127: 435-40.

32. Li GH, Zhang Y, Wu YC, Zhang LD (2005) Photoluminescence of anodic alumina membranes: pore size dependence. Appl Phys A 81: 627-9.

33. Li Z, Huang K (2007) The effect of high-temperature annealing on optical properties of porous anodic alumina formed in oxalic acid. Luminescence 22: $355-61$.

34. Nourmohammadi A, Asadabadi SJ, Yousefi MH, Ghasemzadeh M (2012) Photoluminescence emission of nanoporous anodic aluminum oxide films prepared in phosphoric acid. Nanoscale Res Lett 7: 689.

35. Li Z, Huang KJ (2007) Blue luminescence in porous anodic alumina films. J Phys Condens Mater 19: 216203.

36. Shin S, Kim K, Choi J (2013) Fabrication of ruthenium-doped $\mathrm{TiO}_{2}$ electrodes by one-step anodization for electrolysis applications. Electrochem Commun 36: 88-91.

37. Horcas I, Fernández R, Gómez-Rodríguez JM, Colchero J, Gómez-Herrero J, et al. (2007) WSXM: A software for scanning probe microscopy and a tool for nanotechnology. Rev Sci Instrum 78: 013705.

38. WSxM

39. Gryboś R, Paciorek P, Szklarzewicz JT, Matoga D, Zabierowski P, et al. (2013) Novel vanadyl complexes of acetoacetanilide: Synthesis, characterization and inhibition of proteintyrosine phosphatase. Polyhedron 49: 100-4.

40. Nikolova BM, Nikolov GS (1967) Absorption spectra studies of the citrato complexes of oxovanadium (IV). J Inorg Nucl Chem 29: 1013-20.

41. Kaliva M, Raptopoulou CP, Terzis A, Salifoglou AJ (2003) Systematic studies on pH-dependent transformations of dinuclear vanadium(V)-citrate complexes in aqueous solutions - A perspective relevance to aqueous vanadium(V)-citrate speciation. J Inorg Biochem 93: 161-73.

42. Ding GQ, Yang R, Ding JN, Yuan NY, Zhu YY (2010) Fabrication of porous anodic alumina with ultrasmall nanopores. Nanoscale Res Lett 5: 1257-63.

43. Pashchanka M, Schneider JJ (2011) Origin of self-organisation in porous anodic alumina films derived from analogy with Rayleigh-Bénard convection cells. J Mater Chem 21: 18761-67.

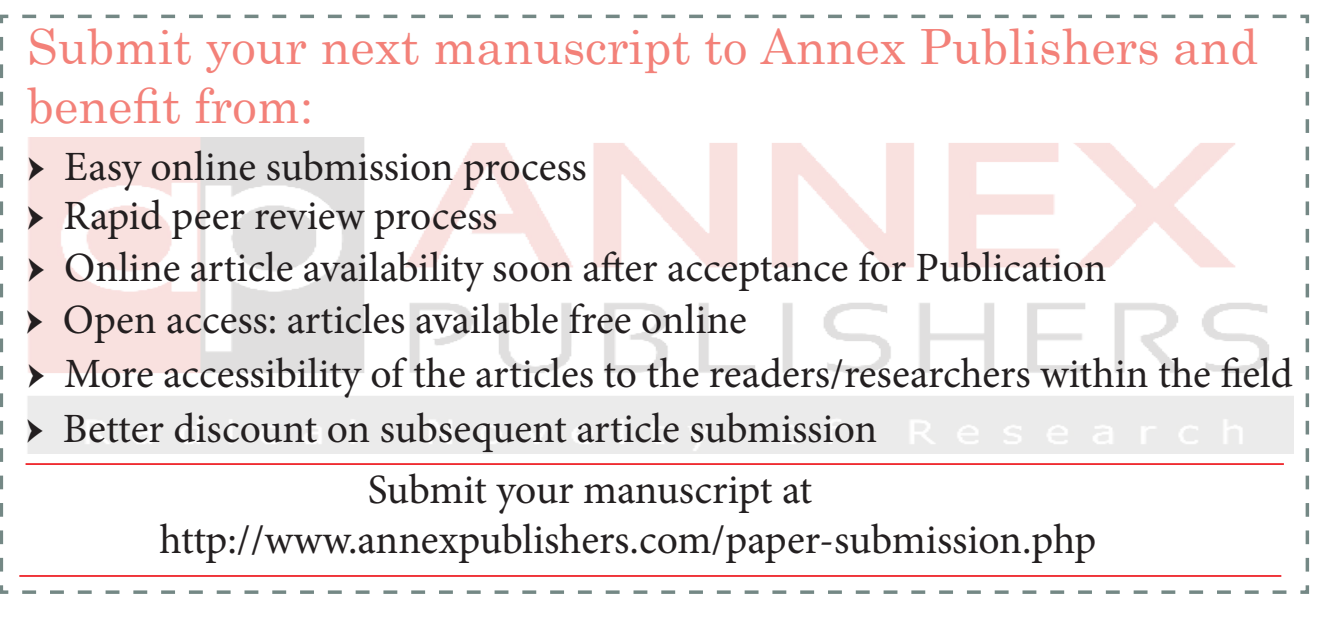

